\title{
A Decline and Age Shift in Malaria Incidence in Rural Mali following Implementation of Seasonal Malaria Chemoprevention and Indoor Residual Spraying
}

\author{
Drissa Coulibaly, ${ }^{1 \star}$ Boureima Guindo, ${ }_{1}$ Amadou Niangaly, ${ }^{1}$ Fayçal Maiga, ${ }^{1}$ Salimata Konate, ${ }^{1}$ Aly Kodio, ${ }^{1}$ Astou Diallo, ${ }^{1}$ \\ Abdou Tahirou Mohamed Antar, ${ }^{1}$ Abdoulaye K. Kone, ${ }^{1}$ Karim Traore, ${ }^{1}$ Mark A. Travassos, ${ }^{2}$ Issaka Sagara, ${ }^{1}$ \\ Ogobara K. Doumbo, ${ }^{1} \dagger$ and Mahamadou A. Thera ${ }^{1}$ \\ ${ }^{1}$ Department of Epidemiology of Parasitic Diseases, Faculty of Medicine and Dentistry, Malaria Research and Training Center, University of \\ Sciences, Techniques and Technologies of Bamako, Bamako, Mali; ${ }^{2}$ Malaria Research Program, Center for Vaccine Development and Global \\ Health, University of Maryland School of Medicine, Baltimore, Maryland
}

\begin{abstract}
Many African countries have reported declines in malaria incidence, attributed to the implementation of control strategies. In Mali, artemisinin-based combination therapy (ACT) was introduced in 2004, and long-lasting insecticide-treated nets (LLINs) have been partially distributed free of charge since 2007. In the Malian town of Bandiagara, a study conducted from 2009 to 2013 showed a stable incidence of malaria compared with 1999, despite the implementation of ACTs and LLINs. Since 2016, seasonal malaria chemoprevention has been scaled up across the country. In addition to these strategies, the population of Bandiagara benefited from indoor residual spray implementation in 2017 and 2018 and continued universal bed net coverage. This study aimed to measure the incidence of malaria in Bandiagara, given this recent scaling up of control strategies. A cohort of 300 children aged 6 months to 15 years was followed up from October 2017 to December 2018. We performed monthly cross-sectional surveys to measure anemia and the prevalence of malaria infection by microscopy. The overall incidence of symptomatic malaria was 0.5 episodes/ person-year. Malaria incidence in children up to 5 years old significantly declined since 2012 and since 1999 (incidence rate ratio estimates: 6.7 [95\% Cl: 4.2-11.4] and 13.5 [95\% Cl: 8.4-22.7]), respectively. The average prevalence of malaria parasitemia was $6.7 \%$. Malaria incidence was higher in children older than 5 years than in those younger than 5 years, highlighting the need to extend malaria control efforts to these older children.
\end{abstract}

\section{INTRODUCTION}

Malaria remains one of the deadliest infections globally. In 2018, the WHO estimates that 219 million cases of malaria occurred worldwide. Africa accounted for $93 \%$ of the cases. ${ }^{1}$ Over the last decade, remarkable achievements in malaria control have been accomplished through large-scale implementation of high-impact interventions, including case management with the rapid diagnostic test (RDT) and treatment with artemisinin-based combination therapy (ACT), prevention and control of malaria among pregnant women using intermittent preventive therapy, vector control strategies including insecticide-treated bed nets (ITNs), and indoor residual spraying (IRS). ${ }^{2-5}$

In Mali, malaria is characterized by its endemicity in the central and southern regions and epidemic potential in the northern regions. Since 2007, children aged 0-5 years have benefited from several malaria control interventions provided free of charge. These include long-lasting insecticide-treated nets (LLINs), RDTs, and ACTs. These strategies have had an impact on morbidity and mortality related to malaria. ${ }^{6}$

A new strategy, seasonal malaria chemoprevention (SMC), appears to have considerable benefits for young children. Children aged 3-59 months receive a treatment dose of amodiaquine plus sulfadoxine-pyrimethamine monthly for 4 months during malaria transmission season. A study measuring the impact of the routine implementation of SMC showed a substantial reduction of malaria and anemia. ${ }^{7}$ The parasitemia prevalence decreased to $18 \%$ in the intervention

*Address correspondence to Drissa Coulibaly, Department of Epidemiology of Parasitic Diseases, Faculty of Medicine and Dentistry, Malaria Research and Training Centre, University of Sciences, Techniques and Technologies of Bamako, Mali P.O. Box: 1805, Point G, Bamako, 1805 Mali. E-mail: coulibalyd@icermali.org †Deceased district and increased to $46 \%$ in the comparison district. $^{7}$ Another study showed an association of the SMC with a substantial reduction in hospital admissions and all-cause mortality. ${ }^{8}$ In 2016, SMC was implemented nationwide for children aged 3 months -5 years.

Bandiagara is a central Mali town that is a sentinel site of the National Malaria Control Program (NMCP) and malaria vaccine testing site. A study carried out in Bandiagara from 2009 to 2013 following the implementation of LLINs, RDTs, and ACTs showed a stable malaria incidence compared with 1999. ${ }^{9}$ Since that study, SMC has been implemented in Bandiagara, as well as universal bed net coverage and IRS in 2017 and 2018. We hypothesized that the implementation of SMC and IRS may reduce the incidence of clinical malaria and malaria infection in Bandiagara.

\section{MATERIAL AND METHODS}

Study design. A cohort study was carried out in children aged between 6 months and 15 years. They were followed from October 2017 to December 2018 by the Malaria Research and Training Center (MRTC) within the Bandiagara Malaria Project (BMP).

Study area. This study was conducted in Bandiagara, a town of approximately 20,000 inhabitants located in central region of Mali in West Africa, on a rocky plain. Bandiagara is a sentinel site of the NMCP and a research site for the MRTC since 1998, and it has been developed as a malaria vaccine testing site. Mosquitoes in the Anopheles gambiae s.l. complex are the main malaria vectors. Malaria transmission is highly seasonal, with minimal transmission during the dry season spanning from November/December to May/June with essentially no detectable infective mosquito bites. Transmission occurs mainly during the rainy season from June/July to October/November, with a peak of up to 60 
infective mosquito bites per person per month in August or September. Plasmodium falciparum represents $97 \%$ of malaria infections, with the remaining $3 \%$ due mostly to Plasmodium malariae and rare Plasmodium ovale infections. The peak of symptomatic malaria occurs in September-October. A detailed description of the study site can be found elsewhere. ${ }^{9}$

In 1999, we performed a cohort study of 401 participants aged from 3 months-20 years, followed up from June to December, that has previously been described. ${ }^{10}$ In brief, subjects were enrolled and followed up passively (which consisted of making available care any time a subject got sick) and actively through weekly clinical evaluations and thick blood smears every 4 weeks. Another cohort of 300 children aged 0-6 years and 100 children aged $7-14$ years were enrolled in June 2009 and June 2010, respectively, and followed up until January 2015 through monthly active visits (with clinical and laboratory assessment) and passively. ${ }^{9}$ For both studies, malaria diagnosis was based on slide microscopy.

Subject recruitment and enrollment. Before starting the study, community permission was obtained as described by Diallo et al. ${ }^{11}$ Parents were invited to accompany children to the BMP Research Clinic to be screened for eligibility. In October 2017, participants were enrolled on a first-come firstserved basis until the study target number was reached.

Inclusion and exclusion criteria. Children aged 6 months-15 years inclusive at the time of screening residing in Bandiagara town and meeting the following inclusion criteria were enrolled: general good health based on clinical evaluation, written informed consent obtained from the parent/guardian, assent from children aged 13 years and older, and availability to participate in follow-up for the duration of study.

Exclusion criteria were simultaneous participation in an interventional clinical trial and chronic use of a medication with known antimalarial activity such as trimethoprim-sulfamethoxazole.

Malaria preventive measures implementation. The distribution campaign of LLINs was in September 2017. Longlasting insecticide-treated nets have been freely distributed to all the population of Bandiagara in the ratio of one LLIN per two persons. There was no LLIN distribution in 2018.

Four rounds of SMC focused on children aged 3-59 months were completed each year in 2017 and 2018. In 2017, the SMC campaigns were from 2 to 6 August, 12 to 16 September, 19 to 23 October, and 28 November to 2 December. In 2018, the SMC rounds were from 20 to 24 July, 24 to 28 August, 22 to 26 September, and 24 to 28 October.

Indoor residual spraying was performed in July 2017 and in September 2018. The insecticide used was Actellic 300 CS (Syngenta Crop Protection AG, Basel, Switzerland).

The Mali NMCP implemented all of these interventions. According to the local NMCP worker responsible for malaria control, the targeted population coverage rate for each intervention exceeded $85 \%$.

Ethical clearance. The study protocol and informed consent/ assent process were reviewed and approved by the institutional review boards of the Faculty of Medicine, Pharmacy, and Dentistry of the University of Science, Techniques, and Technologies of Bamako. Permission to work in the community was obtained from local official authorities. Individual written informed consent was obtained from parents or guardians, and assent was obtained from children aged 13 years and older.

Study procedures. Passive and active surveillance were performed to capture malaria infection and disease.
Active surveillance consisted of scheduled monthly visits (every 4 weeks) with the aim of detecting asymptomatic malaria infection and anemia. At each visit, participants were questioned for symptoms of malaria and examined. Finger prick blood was collected for malaria thick smear and hemoglobin level. Smears were not read contemporaneously unless symptoms or signs of malaria were present.

Passive surveillance consisted of continuous availability of free, basic medical care at the BMP Research Clinic and Bandiagara District Hospital. Parents/guardians were encouraged to visit the clinic at any time when their child got sick. Children were examined by a physician. If symptoms or signs compatible with malaria were present, finger prick blood was collected for a blood film, which was read immediately. Uncomplicated malaria was treated with artemisinin combination therapy (artemether/lumefantrine) according to the guidelines of the Mali NMCP. Parents/guardians were instructed to administer only drugs given or prescribed by the research team and to avoid as much as possible self-medication.

Clinical malaria was defined by the presence of symptoms consistent with malaria: fever, chills, headaches, joint pain, vomiting, diarrhea, or abdominal pain and presence of asexual malaria parasites at any density.

Malaria diagnosis was based on microscopy.

Anemia was defined as a hemoglobin level $<10 \mathrm{~g} / \mathrm{dL}$.

Sample size estimation. To adequately estimate malaria incidence assuming an average of 0.75 clinical episodes per subject per year, we determined that with 300 total subjects, we could assess the malaria incidence in the cohort with $80 \%$ power and a confidence level of $95 \%$.

Laboratory assays. Malaria thick smears were Giemsastained and parasites counted against 300 leukocytes to give parasite counts $/ \mathrm{mm}^{3}$, assuming a leukocyte count of 7,500 / $\mathrm{mm}^{3}$. Standard operating procedures were developed to ensure uniform and high-quality malaria smears, including training and certified malaria microscopists. Hemoglobin level was determined using Hemocue hemoglobin analyzers (Hemocue Inc, Cypress, CA).

Statistical methods. Data were entered into a Microsoft ACCESS 2013 database (Microsoft Corp., Redmond, WA). The analysis was performed using STATA software, version 16 (Stata Corp, College Station, TX). Descriptive statistics were used to summarize baseline values and demographic characteristics (age, gender, and ethnicity). Pearson chi-square

TABLE 1

Sociodemographic and baseline characteristics

\begin{tabular}{lrr}
\hline $\begin{array}{l}\text { Gender } \\
\text { Male }\end{array}$ & $146(48.7)$ & $N(\%)$ \\
$\quad$ Female & $154(51.3)$ & \\
Gender-ratio & & \\
Age & & \\
6 months-5 years & 83 & $27.7 \%$ \\
6-10 years & 110 & $36.7 \%$ \\
> 10 years & 107 & $35.7 \%$ \\
Ethnicity & & \\
Dogon & 200 & 66.7 \\
Sonrhaï & 28 & 9.3 \\
Peulh & 17 & 5.7 \\
Bambara & 13 & 4.4 \\
Soninké & 7 & 2.3 \\
Minianka & 6 & 2.0 \\
Other & 29 & 9.6 \\
\hline
\end{tabular}


TABLE 2

Number of participants who experienced clinical malaria by age-group Clinical episode $\quad 6$ months -5 years, $n(\%) \quad 6-10$ years, $n(\%) \quad>10$ years, $n(\%) \quad$ Total

\begin{tabular}{lrrrr}
\hline 0 & $43(22.3)$ & $76(39.4)$ & $74(38.3)$ & 193 \\
1 & $9(14.5)$ & $19(30.7)$ & $34(54.8)$ & 62 \\
2 & $5(15.6)$ & $18(56.3)$ & $9(28.1)$ & 32 \\
3 & $0(0)$ & $4(36.4)$ & $7(63.6)$ & 11 \\
4 & $0(0)$ & $0(0)$ & $2(100)$ & 2 \\
Total & $57(19.0)$ & $117(39.0)$ & $126(42.0)$ & 300 \\
\hline
\end{tabular}

tests or exact probabilities statistics were used to compare categorical variables.

The incidence rate of clinical malaria was calculated as the number of episodes per person per year. The incidence rate ratio (IRR) with $95 \% \mathrm{Cl}$ was used to compare the incidences by age-groups. Data from 1999 to 2012 have been used for previous studies. Fisher test was used to compare the monthly prevalences between age-groups. $X^{2}$ test was used to compare the cumulative prevalences. All $P$-values $<0.05$ were considered statistically significant.

\section{RESULTS}

Sociodemographic and baseline characteristics. A total of 326 participants were screened. Of these, 300 volunteers who met the inclusion criteria were enrolled. The main reason for noninclusion was likelihood of traveling out of the study area. The gender ratio was 1.05 in favor of girls (154 females versus 146 males; Table 1). The mean age was 7.9 years (Standard Error $0.2 \mathrm{Cl} 95 \%$ [7.5-8.4]). Dogon was the main ethnic group (74\%).

Approximately 98\% (298/300) of children reported sleeping under ITNs during the enrollment visit.

Fourteen participants (4.6\%) were lost to follow-up because of travel. The follow-up rate was $95.4 \%$.

Clinical malaria. Of the 300 participants, 107 experienced at least one clinical malaria episode, with a total of 167 clinical malaria episodes. Two participants had four episodes.

Most children who experienced one episode were older than 10 years (54.8\%; Table 2). By contrast, most participants who experienced two clinical episodes were aged between 6 and 10 years (56.3\%). Participants younger than 6 years did not experience more than two episodes (Table 2). For participants who experienced three episodes, those older than 10 years were the most represented (63.6\%). Two participants older than 10 years had four episodes.

The overall incidence rate after 16 months of follow-up was 0.5 (95\% Cl: 0.4-0.6) clinical malaria episodes (Table 3). The age-specific incidence was $0.3(95 \% \mathrm{Cl}$ : 0.2-0.5), $0.5(95 \% \mathrm{Cl}$ : 0.4-0.6), and 0.6 (95\% Cl: 0.5-0.7) episodes/person-year, respectively, in children aged 6 months -5 years, $6-10$ years, and older than 10 years categories.

The younger age-group was less affected than the 6- to 10year age-group: the IRR estimate was 0.6 (95\% Cl: 0.3-1.0), $P=0.016$ (Table 3).

Malaria incidence in children aged up to 5 years was higher in 2012 than in 2017-2018: the IRR estimate was 6.7 (95\% Cl: 4.2-11.4), $P<10^{-3}$ (Table 3).

Malaria incidence in children aged up to 5 years was much higher in 1999 than in 2017-2018: the IRR estimate was 13.5 (95\% Cl: 8.4-22.7); $P<10^{-3}$ (Table 3).

Participants sampled for parasitemia and the prevalence of infection. The highest cumulative prevalence of infection was $13.5 \%$, in May 2018. The lowest prevalence of infection was 2.0\%, recorded in June 2018 (Table 4, Figure 1). The average prevalence of malaria infection for the study period was $6.8 \%$.

For children older than 10 years, monthly infection prevalence peaked in October 2017 at $18.1 \%$. In the low malaria transmission season spanning December to May, the highest malaria prevalence for these children was 16.5\%, in May 2018. The lowest prevalence of infection in children aged $0-5$ years was 1.2\%, in October 2017 (Table 4, Figure 1). For children aged 6-10 years, no parasites were detected in this population in June 2018. In October 2017, the prevalence of infection was low in children aged from 6 months -5 years compared with that in those aged $6-10$ years $(P=0.026)$ and in those older than 10 years $\left(P<10^{-3}\right)$. Overall, there was a statistically significant difference between age-group $\left(X^{2}=16.86 ; P<10^{-3}\right)$. The cumulative prevalence in children aged up to 5 years and children aged $6-10$ years was comparable $\left(X^{2}=0.05 ; P=\right.$ 0.833), whereas children older than 10 years had a higher

TABLE 3

Comparison of clinical malaria incidence rates by age-group and year

Incidence rate of clinical malaria by age-group in 2017-18

\begin{tabular}{|c|c|c|c|c|c|c|}
\hline & 6 months -5 years & $6-10$ years & $>10$ years & Overall & $\operatorname{IRR}^{\star}(95 \% \mathrm{Cl}), P$ & IRRT $(95 \% \mathrm{Cl}), P$ \\
\hline Number of episodes & 19 & 67 & 81 & 167 & $0.6(0.4-1.0), 0.016$ & $0.51(0.3-0.9), 0.005$ \\
\hline Person-year & 64.8 & 133.2 & 141.3 & 339.3 & & \\
\hline Incidence rate $(95 \% \mathrm{Cl})$ & $0.3(0.2-0.5)$ & $0.5(0.4-0.6)$ & $0.6(0.5-0.7)$ & $0.5(0.4-0.6)$ & & \\
\hline \multicolumn{7}{|c|}{ Comparison of malaria incidence in children aged up to 5 years in 2012 and $2017-2018$} \\
\hline & 2012 & 2017-2018 & & & IRR $\ddagger(95 \% \mathrm{Cl}), P$ & \\
\hline Number of episodes & 185 & 19 & & & $6.7(4.2-11.4),<10^{-3}$ & \\
\hline Person-year & 94.2 & 64.8 & & & & \\
\hline Incidence rate $(95 \% \mathrm{Cl})$ & $2.0(1.7-2.3)$ & $0.3(0.2-0.5)$ & & & & \\
\hline \multicolumn{7}{|c|}{ Comparison of malaria incidence in children aged up to 5 years in 1999 and $2017-2018$} \\
\hline & 1999 & $2017-2018$ & & & IRR§ (95\% Cl), $P$ & \\
\hline Number of episodes & 245 & 19 & & & $13.5(8.4-22.7),<10^{-3}$ & \\
\hline Person-year & 62.1 & 64.8 & & & & \\
\hline Incidence rate $(95 \% \mathrm{Cl})$ & $3.9(3.5-4.5)$ & $0.3(0.2-0.5)$ & & & & \\
\hline
\end{tabular}

IRR = incidence rate ratio.

${ }^{*}$ IRR = comparison of malaria incidence in children aged up to 5 years and children older than 10 years in 2017-2018.

†IRR = comparison of malaria incidence in children aged up to 5 years and children aged from 6 to 10 years in 2017-2018.

†IRR = comparison of malaria incidence in children aged up to 5 years in 2012 and 2017-2018.

$\S \mathrm{IRR}=$ comparison of malaria incidence in children aged up to 5 years in 1999 and 2017-2018. 
TABLE 4

Monthly prevalence of malaria infection

\begin{tabular}{|c|c|c|c|c|c|c|c|c|}
\hline \multirow[b]{2}{*}{ Month } & \multicolumn{2}{|c|}{6 months -5 years } & \multicolumn{2}{|c|}{$6-10$ years } & \multirow[b]{2}{*}{$P$-value ${ }^{\star}$} & \multicolumn{2}{|c|}{$>10$ years } & \multirow[b]{2}{*}{$P$-value $†$} \\
\hline & Negative, $n$ & Positive, $n(\%)$ & Negative, $n$ & Positive, $n$ (\%) & & Negative, $n$ & Positive, $n$ (\%) & \\
\hline October 2017 & 81 & $1(0.2)$ & 100 & $10(9.1)$ & 0.026 & 86 & $19(18.1)$ & $<10^{-3}$ \\
\hline November 2017 & 77 & $2(2.5)$ & 106 & $4(3.6)$ & 1.000 & 102 & $6(5.5)$ & 0.471 \\
\hline December 2017 & 76 & $3(3.8)$ & 100 & $6(5.6)$ & 0.735 & 105 & $6(5.4)$ & 0.738 \\
\hline January 2018 & 78 & $2(2.5)$ & 100 & $6(5.6)$ & 0.469 & 104 & $8(7.1)$ & 0.198 \\
\hline February 2018 & 76 & $3(3.8)$ & 102 & $5(4.6)$ & 1.000 & 100 & 13 (11.5) & 0.067 \\
\hline March 2018 & 67 & $9(11.8)$ & 99 & $8(7.4)$ & 0.439 & 103 & $11(9.6)$ & 0.637 \\
\hline April 2018 & 70 & $3(4.1)$ & 108 & $3(2.7)$ & 0.683 & 109 & $3(2.6)$ & 0.682 \\
\hline Early May 2018 & 61 & $10(14.0)$ & 99 & $11(9.9)$ & 0.478 & 96 & 19 (16.5) & 0.836 \\
\hline Late May 2018 & 69 & $3(4.2)$ & 106 & $3(2.7)$ & 0.683 & 110 & $6(5.1)$ & 1.000 \\
\hline June 2018 & 66 & $2(2.9)$ & 109 & 0 & 0.146 & 112 & $4(3.4)$ & 1.000 \\
\hline July 2018 & 60 & $6(9.1)$ & 99 & $8(7.5)$ & 0.777 & 98 & $11(10.1)$ & 1.000 \\
\hline August 2018 & 59 & $5(7.8)$ & 102 & $7(6.4)$ & 0.762 & 98 & 13 (11.7) & 0.606 \\
\hline September 2018 & 58 & $4(6.4)$ & 98 & $8(7.5)$ & 1.000 & 99 & 13 (11.6) & 0.424 \\
\hline October 2018 & 59 & $3(4.8)$ & 100 & $8(7.4)$ & 0.748 & 106 & 7 (6.2) & 1.000 \\
\hline November 2018 & 52 & $3(5.4)$ & 103 & $5(4.6)$ & 1.000 & 112 & 7 (5.9) & 1.000 \\
\hline December 2018 & 51 & $3(5.5)$ & 103 & 7 (6.4) & 1.000 & 107 & $12(10.1)$ & 0.396 \\
\hline Total & 1,060 & $62(5.5)$ & 1,634 & $99(5.7)$ & 0.868 & 1,647 & $158(8.7)$ & 0.001 \\
\hline
\end{tabular}

${ }^{\star} P$-value $=$ comparison of children aged 6 months -5 years with 6 - to 10 -year-old children.

$\dagger P$-value $=$ comparison of children aged 6 months -5 years with children older than 10 years.

prevalence than those aged $0-5$ years $\left(X^{2}=10.37 ; P=0.001\right.$; Table 4).

Prevalence of anemia. The overall prevalence of anemia was $2.3 \%$ (Figure 2). The highest prevalence of anemia was
$7.1 \%$, in November 2018. For children aged 0-5 years, the highest prevalence of anemia was 18.2\%, in November 2018. For children older than 10 years, monthly anemia prevalence did not exceed $5 \%$ during the entire study (Figure 2). There

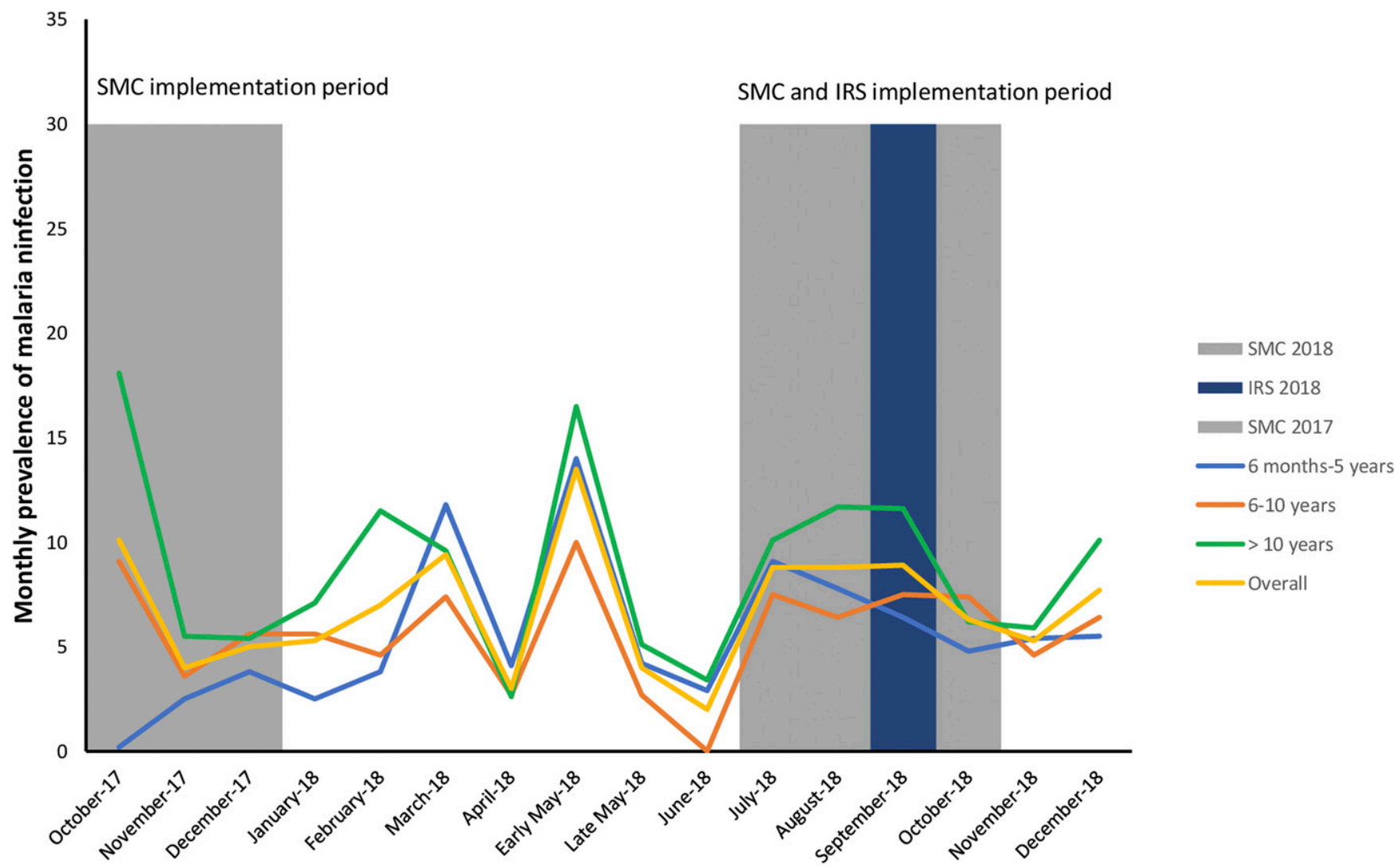

Time-series

FIGURE 1. Gray vertical bars cover the seasonal malaria chemoprevention implementation period in 2017 and 2018 , blue vertical bar covers the IRS implementation period in 2018, blue line represents the monthly prevalence of malaria infection in children aged 0-5 years, red line represents the monthly prevalence of malaria infection in children aged 6-10 years, green line represents the monthly prevalence of malaria infection in children older than 10 years, and orange line represents the overall monthly prevalence of malaria infection. This figure appears in color at www.ajtmh.org. 


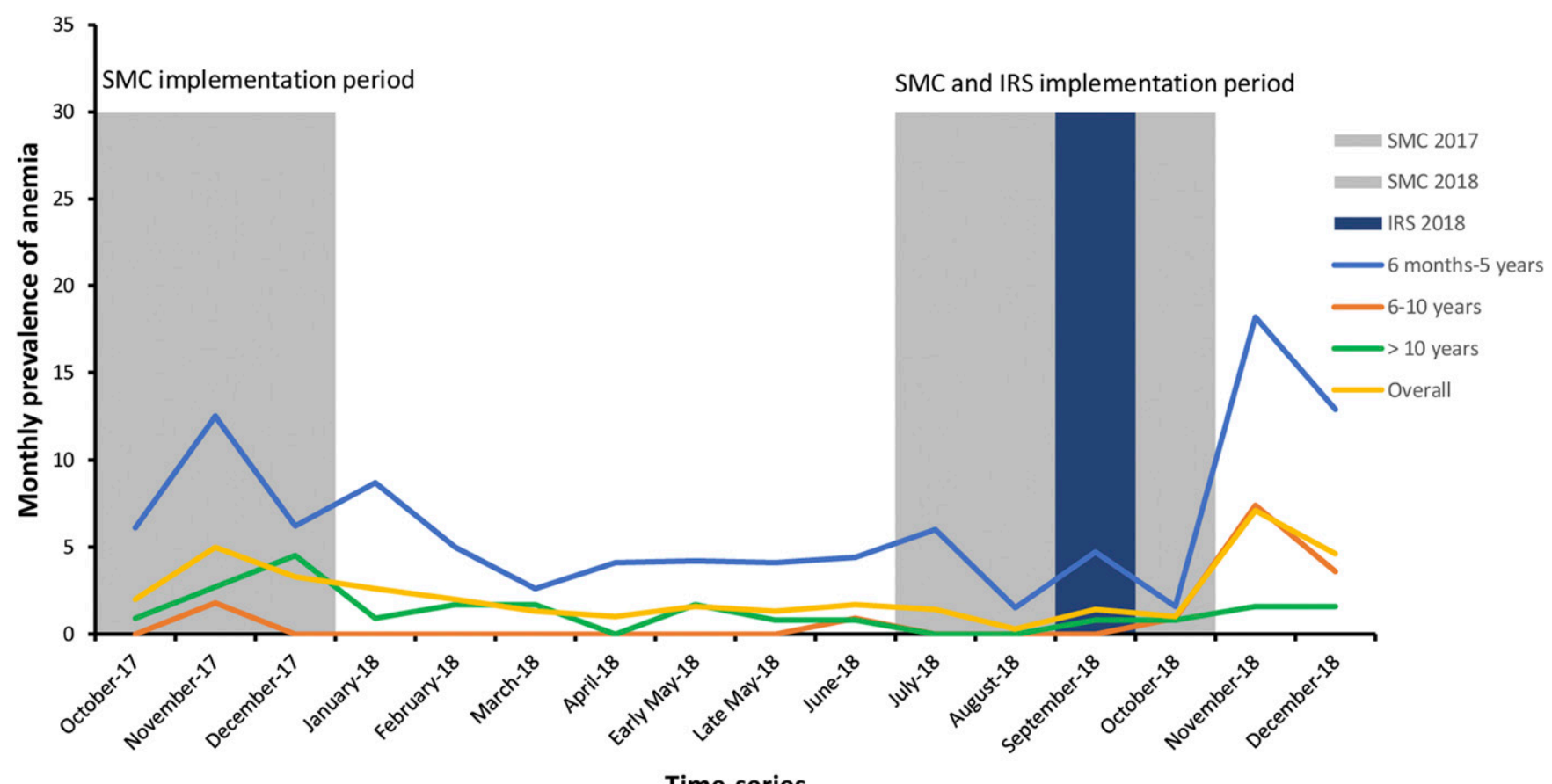

Time-series

FIGURE 2. Gray vertical bars cover the seasonal malaria chemoprevention implementation period in 2017 and 2018 , blue vertical bar covers the IRS implementation period in 2018 , blue line represents the monthly prevalence of anemia in children aged 0-5 years, red line represents the monthly prevalence of anemia in children aged 6-10 years, green line represents the monthly prevalence of anemia in children older than 10 years, and orange line represents the overall monthly prevalence of anemia. This figure appears in color at www.ajtmh.org.

was a significant difference in anemia prevalence between age-groups $\left(X^{2}=99.36 ; P<10^{-3}\right)$.

\section{DISCUSSION}

Tools and strategies for malaria control such as ACT, longlasting ITNs, intermittent preventive treatment in pregnancy, intermittent preventive treatment in infancy, and SMC in children have shown efficacy in malaria control. ${ }^{1,12}$ In Bandiagara, following implementation of long-lasting ITNs, RDTs, and ACT, a study showed a comparable incidence to what was observed in 1999, before implementation of these control strategies. ${ }^{9}$ Seasonal malaria chemoprevention was scaled up in 2016 in Mali, and in 2017-2018, the health district of Bandiagara benefited from a large distribution of long-lasting ITNs and IRS. As new interventions need to be monitored for proper implementation and potential impact, we measured the incidence of malaria in the pediatric population, predicting a decline.

A cohort of 300 children was followed up using active and passive surveillance to capture all clinical episodes of malaria that occurred in the cohort during the study period. The cumulative prevalence of malaria parasite carriage was $6.8 \%$. A survey carried out from August to October 2010 (before SMC and IRS implementation), in children aged 6-59 months, showed a prevalence of $47.4 \%$ of Plasmodium carriage in the Mopti region, which includes Bandiagara. ${ }^{13}$ The low prevalence of malaria infection that we observed attests to a reduction in transmission intensity and may be due to the combination of SMC, LLINs, and IRS in Bandiagara. Interestingly, the highest prevalence of infection was observed in the dry season, when all parasite carriers were asymptomatic. The highest prevalence of malaria infection was noted then in children older than 10 years. There was a statistically significant difference when comparing the cumulative prevalence in children up to 5 years old and children older than 10 years $(P=0.001)$. Similar findings have been noted in Senegal. In a cluster-randomized trial evaluating the effectiveness of SMC using sulfadoxine-pyrimethamine plus amodiaquine given over 5 months to children younger than 10 years in Saraya district, the prevalence of parasitemia was $18 \%$ in children younger than 5 years and $25 \%$ in children aged 5-9 years in the control villages, and $5.7 \%$ and $5.8 \%$, respectively, in these two age-groups in the SMC villages, with prevalence differences of $12.5 \%$ (95\% Cl: 6.8-18.2; $P<0.001)$ in children younger than 5 years and $19.3 \%(95 \% \mathrm{Cl}: 8.3-30.2$; $P<0.001)$ in children aged $5-9$ years. ${ }^{14}$

We found an overall malaria incidence rate of 0.5 episodes/ person-year; the age-specific incidence was $0.3,0.5$, and 0.6 episodes per person-year observed, in children aged 6 months -5 years, $6-10$ years, and older than 10 years groups, respectively. Children aged 6 months -5 years had a lower malaria incidence than those aged $6-10$ years and than children older than 10 years. This is unusual, given that in hightransmission settings, the highest malaria incidence has classically been seen in younger children. ${ }^{17}$ These findings parallel the age shift in the susceptibility to malaria recently reported by authors in regions where similar control strategies were implemented. ${ }^{7,12,13}$

We found a significant decrease in malaria incidence compared with older studies. Previous studies in Bandiagara determined an incidence of malaria of 1.7 episodes per person/ 24 weeks in 1999, and 1.4 episodes per person-years from 2009 to 2013. Malaria incidence in children aged up to 5 years 
significantly declined since 2012 and since 1999. The decrease in malaria incidence established by this current study is likely due to the efficacy of control measures, particularly the recent implementation of SMC and IRS, as well as longstanding measures such as LLINs, suggesting that malaria may be eliminated with the proper implementation of all of the prevention tools available today.

The prevalence of anemia rose in October 2018, peaking at $18.2 \%$ the following month in the 0 - to 5 -year age-group. The prevalence remained less than $5 \%$ in older age-groups irrespective of month. This rise paralleled a rise in malaria prevalence, but other contributors to anemia include malnutrition. At our study site, a food shortage is generally observed from August to December, which could contribute to the high prevalence of anemia in that period in young children, who are also more susceptible to other infections than older children. A similar finding was observed in Nigeria, where a study conducted in 226 children aged up to 10 years showed the highest prevalence of anemia in children aged $\leq 1-2$ years $(P=0.003)$. Only $4.9 \%$ of children were using ITN. ${ }^{15}$ In addition, a review of malaria and anemia showed a decline of anemia in high malaria transmission settings when children grow. ${ }^{16}$

Limitations of this study include the lack of entomological parameters of transmission to support clinical findings, the relative short study period, and the lack of information on SMC receipt for participants younger than 5 years. However, according to the person in charge of malaria in the district health referral center, overall, the SMC coverage rate is more than $85 \%$.

We identified a decline in malaria incidence at a Malian site with intense seasonal transmission following the combined implementation of control strategies that included SMC and IRS. Old children experienced more malaria cases. This finding supports the extension of control efforts to older agegroups.

Received June 8, 2020. Accepted for publication December 16, 2020.

Published online March 1, 2021.

Acknowledgments: We thank Ibrahima Kebe, and Ismael Thera for data management; Abdoulaye Ouologuem, Boucari Djiguiba, Sadio Dolo, Domo Ouologuem, Issa Tapily, and Paul Dougnon for fieldwork; Danzélé Coulibaly, Sékouba Mariko, and Mali Service Center for administrative and technical support; Abdoul Karim Doumbia, the medical chief officer of the Bandiagara District Hospital, for support; and the study participants.

Financial support: This work was supported through the DELTAS Africa Initiative grant DEL-15-10. The DELTAS Africa Initiative is an independent funding scheme of the African Academy of Sciences (AAS)'s Alliance for Accelerating Excellence in Science in Africa (AESA) and supported by the New Partnership for Africa's Development Planning and Coordinating Agency (NEPAD Agency), with funding from the Wellcome Trust grant 107741/A/15/Z and the UK government. Malaria Research and Capacity Development (MARCAD), a DELTAS Program, supported Drissa Coulibaly through a Postdoctoral fellowship. The views expressed in this publication are those of the author(s) and not necessarily those of AAS, NEPAD Agency, Wellcome Trust or the UK government.

Disclaimer: The views expressed in this publication are those of the author(s) and do not necessarily represent those of AAS, NEPAD Agency, Wellcome Trust, or the UK government.

Authors' addresses: Drissa Coulibaly, Boureima Guindo, Amadou Niangaly, Fayçal Maiga, Salimata Konate, Aly Kodio, Astou Diallo, Abdou Tahirou Mohamed Antar, Abdoulaye K. Kone, Karim Traore, Issaka Sagara, Ogobara K. Doumbo, and Mahamadou A. Thera,
Department of Epidemiology of Parasitic Diseases, Faculty of Medicine and Dentistry, Malaria Research and Training Center, University of Science, Techniques and Technologies of Bamako, Bamako, Mali, E-mails: coulibalyd@icermali.org, bguindo@icermali.org, niangaly@ icermali.org, fmaiga66@yahoo.fr, sakonate@icermali.org, alkodio@ icermali.org, atoutaaa@gmail.com, antar.mohamed1@icloud.com, fankone@icermali.org, karim@icermali.org, isagara@icermali.org, okd@ icermali.org, and mthera@icermali.org. Mark A. Travassos, Malaria Research Program, Center for Vaccine Development and Global Health, University of Maryland School of Medicine, Baltimore, MD, E-mail: mtravass@som.umaryland.edu.

This is an open-access article distributed under the terms of the Creative Commons Attribution (CC-BY) License, which permits unrestricted use, distribution, and reproduction in any medium, provided the original author and source are credited.

\section{REFERENCES}

1. WHO, 2019. World Malaria Report 2019. Geneva, Switzerland: World Health Organization. Available at: https://www.who.int/ publications-detail/world-malaria-report-2019. Accessed May 11, 2020.

2. Abeku TA et al., 2015. Monitoring changes in malaria epidemiology and effectiveness of interventions in Ethiopia and Uganda: beyond Garki Project baseline survey. Malar J 14: 337.

3. Cotter C, Sturrock HJW, Hsiang MS, Liu J, Phillips AA, Hwang J, Gueye CS, Fullman N, Gosling RD, Feachem RGA, 2013. The changing epidemiology of malaria elimination: new strategies for new challenges. Lancet 382: 900-911.

4. Gething PW et al., 2016. Mapping Plasmodium falciparum mortality in Africa between 1990 and 2015. N Engl J Med 375: 2435-2445.

5. Deribew A et al., 2017. Incidence, prevalence and mortality rates of malaria in Ethiopia from 1990 to 2015: analysis of the global burden of diseases 2015. Malar J 16: 271.

6. Kayentao K, Florey LS, Mihigo J, Doumbia A, Diallo A, Koné D, Doumbo O, Eckert E, 2018. Impact evaluation of malaria control interventions on morbidity and all-cause child mortality in Mali, 2000-2012. Malar J 17: 424.

7. Diawara F et al., 2017. Measuring the impact of seasonal malaria chemoprevention as part of routine malaria control in Kita, Mali. Malar J 16: 325

8. Issiaka D, Barry A, Traore T, Diarra B, Cook D, Keita M, Sagara I, Duffy $P$, Fried M, Dicko A, 2020. Impact of seasonal malaria chemoprevention on hospital admissions and mortality in children under 5 years of age in Ouelessebougou, Mali. Malar $J$ 19: 103.

9. Coulibaly $D$ et al., 2014. Stable malaria incidence despite scaling up control strategies in a malaria vaccine-testing site in Mali. Malar J 13: 374

10. Coulibaly $S$ et al., 2002. Impact of preseason treatment on incidence of falciparum malaria and parasite density at a site for testing malaria vaccines in Bandiagara, Mali. Am J Trop Med Hyg 67: 604-610.

11. Diallo DA, Doumbo OK, Plowe CV, Wellems TE, Emanuel EJ, Hurst SA, 2005. Community permission for medical research in developing countries. Clin Infect Dis 41: 255-259.

12. Greenwood BM, Fidock DA, Kyle DE, Kappe SHI, Alonso PL, Collins FH, Duffy PE, 2008. Malaria: progress, perils, and prospects for eradication. J Clin Invest 118: 1266-1276.

13. Traoré K, Mariko S, Doumbia B, Berthé S, 2010. Enquête sur la prévalence de l'Anémie et de la Parasitémie palustre chez les enfants (EA\&P) au Mali 2010.

14. Ndiaye JLA et al., 2019. Seasonal malaria chemoprevention combined with community case management of malaria in children under 10 years of age, over 5 months, in south-east Senegal: a cluster-randomised trial. PLoS Med 16: e1002762.

15. Oladeinde $B$, Omoregie R, Olley $M$, Anunibe J, Onifade A, Oladeinde O, 2012. Malaria and anemia among children in a low resource setting in Nigeria. Iran J Parasitol 7: 31-37.

16. White NJ, 2018. Anaemia and malaria. Malar J 17: 1-17.

17. Griffin JT, Ferguson NM, Ghani AC, 2014. Estimates of the changing age-burden of Plasmodium falciparum malaria disease in sub-Saharan Africa. Nat Commun 5: 3136. 